\section{More creativity wanted}

ONCE again the Japanese government is calling for "more basic research and more creativity", in the nation's scientific research programmes.

This time it is the latest White Paper from the Science and Technology Agency that stresses the need for greater efforts. But unlike previous reports, the new paper goes some way towards explaining just why there is so much concern about creativity in Japan.

The 419-page paper, entitled Aiming at the creation of new technology for the 21st century takes as its starting point an attempt to assess just how well Japan's basic research is doing. This is no simple matter, and the report opts for a simple analysis of the number of papers published in important international science journals in three areas: life sciences, materials and surface sciences, and computer architecture and pattern recognition. The first groups are analysed by the number of papers published in Nature and up to seven other international journals, for computers two journals are used.

The results make pretty depressing reading for the Japanese. In materials and surface science, the United States is publishing 25 times more papers a year than Japan, in the computer field 6-8 times more, and in life science 5 times more. Comparison with "Europe" (here taken as the United Kingdom, West Germany and France) paints a more favourable picture: Europe produces five times more papers in materials and surface science but only about 20 per cent more in computer and life sciences. For the Japanese though, it is the comparison with the United States that really counts; Europe has long been written off as a supplier of rock music, fashion and sausages rather than a serious technological competitor.

Part - but not all - of the discrepancy between Japan and the United States is accounted for in terms of the difference in funding. Japan's total expenditure and basic research is obviously less than that of the United States but, as the White Paper shows, at 35 per cent of the US total is not so much less as might be expected. The percentage of funds going to basic research in Japan is, however, on the decline down to 14.6 per cent in 1982 from 24 per cent a decade ago - despite endless government calls for more attention to basic research. But the trend is not so hard to explain. The bulk of the Japanese research effort (and funds) is provided by industry, where expenditure has been increasing with great rapidity. Expenditure in the universities and institutes where basic research is carried out has simply not kept pace with industrial expansion. Not surprisingly, the expanding industrial laboratories are largely concerned with applied research.
Indeed, the report also gives figures suggesting that the whole thrust of science education is away from the basic towards the applied. Japanese universities produce a staggering number of engineers - more in total than the United States, even though the actual number of university students in the United States is five times higher. In contrast, the United States and the United Kingdom produce huge numbers of graduates in the natural sciences (among graduates, the ratio of engineers to scientists is 6.4 in Japan, 0.8 in the United States and 0.6 in the United Kingdom). Not surprisingly, given the bias towards engineering, most graduates quickly make their way into industrial companies; only three per cent of Japan's students go on to further university training, whereas in the United States and Europe it is closer to 18 per cent. Indeed, although the United Kingdom has only one seventh the number of undergraduate students as Japan, the nation produces getting on for double the number of doctoral and masters' theses in science.

The report also raises worries over just how well Japan is doing in the technology trade, thought to be a reflection of the development of "'basic'" new industrial processes. Overall, there is no doubt that Japan is massively in the red when it comes to payments for licences and patents. But this is not such a serious problem. Many payments are still being made for technology licensed years ago. When only recent licences are taken into account, then the beginnings of a shift towards a technology trade surplus can be seen.

How then is Japan's basic research performance to be improved? The general suggestions made in the report are familiar ones: funds to cultivate young and talented researchers, increased exchange between universities, industry and government research institutes, greater investment in the equipment and facilities necessary to back up advanced research and increased investment in personnel at the universities and national research in institutes.

If present government policy measures are anything to go by, however, the result will be an increasing basic research and role for private industry. Increased tax incentives for industry to perform basic research and joint research with industry at government research institutes are measures likely to be enacted before long, rather than increased funds for the universities.

\title{
Superconducting supercollider
}

\section{States vie for US accelerator site}

\section{Washington}

THE competition has begun among state governments to play host to the proposed Superconducting Supercollider (SSC). If built - which is still not formally decided - the accelerator will bring millions of dollars and thousands of jobs to the state lucky enough to be selected. And while the Department of Energy insists that the site will be selected on the best scientific criteria, many states are already letting it be known that a decision in their favour would be rewarded with financial benefits.

SSC, a proton/proton collider, would be easily the world's largest accelerator, with a circumference of between 60 and 100 miles, depending on the type of magnets used. The cost of construction, which would take 6 years, is estimated at $\$ 3,000$ million at 1984 prices. When completed, there might be 2,000 people directly employed.

Texas is making one of the strongest pitches for SSC. Governor Mark White has made it clear that the state will do whatever is necessary to present its case, including making available state funds to assist with the cost of the project. A site selection committee is now at work and has settled on four or five locations. The criteria used include proximity to a large airport, and Houston is seen as a big draw.

Research into a possible magnet design for SSC is being undertaken at the Texas Accelerator Center, which reports encouraging results with superferric magnets.
Peter McIntyre of Texas A\&M University says that completed magnets of the Texas design would cost less than half those of competing high-field designs - $\$ 350$ million as against $\$ 800-\$ 900$ million. The catch is that superferric magnets, with a field strength of 2-3 tesla, require larger tunnels, but McIntyre is confident that the magnet cost saving is decisive.

Texas is faced with strong competition from Illinois, which has already spent $\$ 500,000$ on geological surveys to find a suitable site in the state. One strong attraction is that it might be possible to utilize the proton injector at Fermilab, with a substantial cost saving. In addition, there is already the laboratory infrastructure in place to support scientific staff during construction. Illinois also has a governorappointed task force reviewing possible sites, and local industries have been persuaded to join in. In Colorado, $\$ 200,000$ of state funds have been spent on site selection and universities and industry are combining forces to present a case to the Department of Energy. Other interested states include Utah, Arizona, Michigan and Minnesota.

A document detailing site selection criteria is now being drawn up by the department's contractor, the Universities Research Association, and will be published in April. The race to capture SSC will then be on in earnest if construction is to start as hoped in 1988.
Tim Beardsley 